\title{
Catalysis: A Golden Future
}

\author{
Graham J Hutchings \\ Leverbulme Centre for Innovative Catalysis, \\ Department of Chemistry, \\ University of Liverpool, Liverpool, UK
}

The recent literature concerning the use of supported gold catalysts is reviewed. In particular, two main uses of gold catalysts are considered, namely (a) the hydrochlorination of ethyne using supported chlorides, and (b) the oxidation of carbon monoxide at ambient temperature. For the hydrochlorination of ethyne a correlation of catalytic activity with the metal standard electrode potential predicted that gold would be the most active catalyst for this reaction, and subsequent experimental work confirmed this prediction. Low temperature oxidation of carbon monoxide is a reaction of current environmental interest and gold catalysts are effective at ambient conditions. For both these reactions, gold is found to be the most active catalyst and is therefore the metal of choice.

Two previous reviews of gold catalysts $(1,2)$ have both started with conditional phrases that sought to excuse the low catalytic activity of gold in many applications. For example, in 1972 Bond (1) stated: Although the catalytic properties of gold are surpassed by those of the Group VIII metals, especially palladium and platinum, possible applications of gold in catalytic processes have been widely studied'. In 1985, Schwank commented: 'In spite of its low intrinsic activity, gold can influence the activity and selectivity of Group VIII metals'. Indeed, for many years, gold was known to have poor catalytic activity in many applications. Gold catalysts have been shown to be active for oxidation reactions, e.g. oxidation of sulfides (3) and dithioalkanes (4), dehydogenation reactions, e.g. benzene formation from cyclohexene (5), isomerization, dehydrocyclization and hydrogenolysis reactions, e.g. pentane (6), and oxidative dehydrogenation reactions (1). However, in all these applications, gold systems did not exhibit any significant catalytic advantages over other metal catalyst systems. Many of the previous studies involved the introduction of gold to another, more active, metal to influence the selectivity of the reaction at the expense of activity. Recently (7), it has been pointed out that there is a re-awakening of interest in catalysis by gold species. This is prompted by two discoveries that have shown that the observation of low catalytic activity with gold is not a universal rule, and that gold can be the catalytic metal of choice when it demonstrates the highest catalytic activity. This is the case in the following reactions: (a) the hydrochlorination of ethyne using supported chlorides, (b) the oxidation of carbon monoxide at ambient temperature, and the recent work demonstrating the efficacy of gold is reviewed in this paper.

\section{HYDROCHLORINATION OF ETHYNE}

The heterogeneously catalysed addition of $\mathrm{HCl}$ to ethyne (acetylene) has been used for the industrial manufacture of chloroethene (vinyl chloride).

$$
\mathrm{HC} \equiv \mathrm{CH}+\mathrm{HCl} \rightarrow \mathrm{CH}_{2} \mathrm{CHCl}
$$

Supported metal chlorides $(8-10)$ have been used for this reaction and mercuric chloride supported on carbon has been used industrially $(11,12)$. Mercuric chloride catalysts deactivate quite rapidly under reaction conditions and, in view of the toxicity of these catalysts, there have been a number of studies on the use of alternative catalysts.

Prediction of the enhanced activity of gold catalysts. In the previous studies, carbon was found to be the preferred support (8) since when silica was used some polymerization products were observed (9). Further studies indicated that the rate-determining step involves the addition of $\mathrm{HCl}$ to a surface ethyne complex (13-15): 


$$
\mathrm{MCl}_{\mathrm{n}}+\mathrm{HC} \equiv \mathrm{CH}+\mathrm{HCl} \longrightarrow \mathrm{MCl}_{\mathrm{n}} \cdot \mathrm{HC} \equiv \mathrm{CH} \cdot \mathrm{HCl}
$$

Active catalysts should therefore be able to form surface metal-ethyne and metal $\mathrm{HCl}$ complexes. Metastable acetylides are known for many metals including: $\mathrm{Cu}, \mathrm{Ag}, \mathrm{Au}, \mathrm{Na}, \mathrm{K}, \mathrm{Rb}, \mathrm{Zn}, \mathrm{Cd}, \mathrm{Hg}, \mathrm{Pd}, \mathrm{Os}$, $\mathrm{Ce}, \mathrm{Al}, \mathrm{Mg}, \mathrm{Ca}, \mathrm{Sr}, \mathrm{Ba}$ and are considered possible for $\mathrm{Pt}, \mathrm{Ru}, \mathrm{Rh}$, Ir. The stability of these acetylides can be expected to be an important parameter in controlling the activity of these metals and their salts. Smith et al (9) studied a range of metal chlorides and considered that the activity could be correlated with the electron affinity of the cation. However, one of the most extensive studies of metal chloride catalysts was carried out by Shinoda (10) and with more data the simple correlation with electron affinity was no longer valid. Shinoda considered that a correlation existed with the electron affinity divided by the metal valence (oxidation state) (Figure 1). The correlation consists of two straight lines and cannot be used predictively since it is not possible to determine whether a particular metal will give high or low activity. Shinoda distinguished between the two sets by considering that the lower data set comprised metal cations that formed complexes with $\mathrm{HCl}$ and acted as Friedel Crafts catalysts.

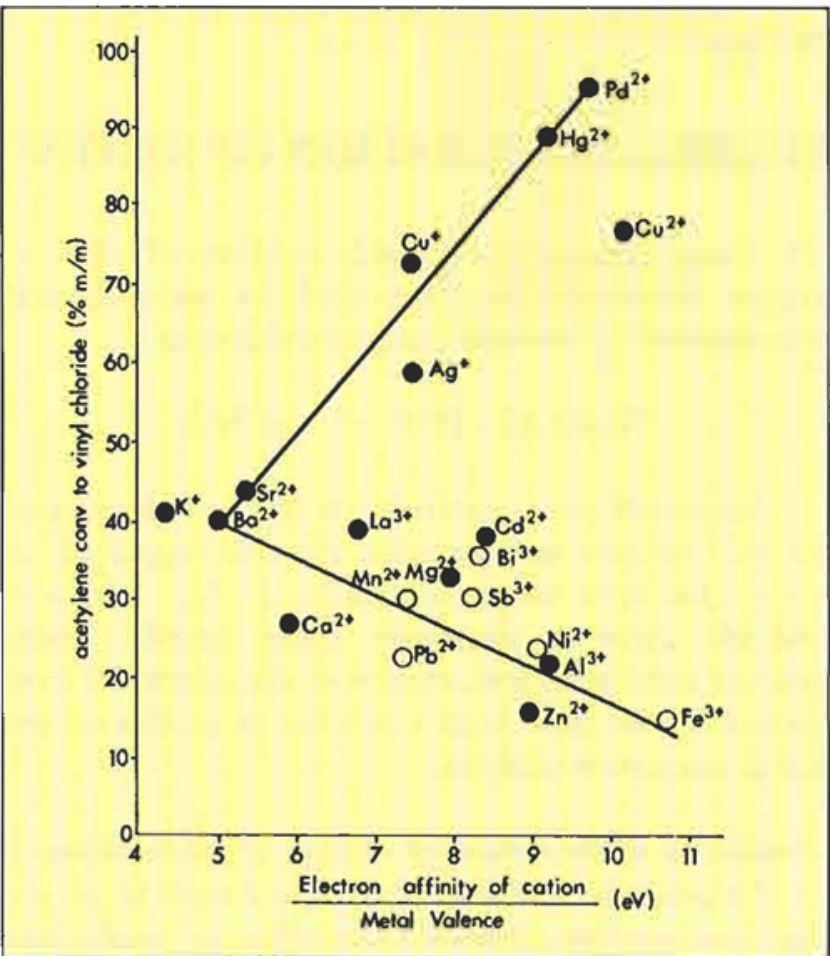

Figure 1 Correlation of hydrochlorination activity of metal chlorides supported on carbon $\left(200^{\circ} \mathrm{C}, G H S V 150\right.$ $\left.b^{-1}\right)$ with the electron affinity of the cation divided by the metal valence (after reference 16).

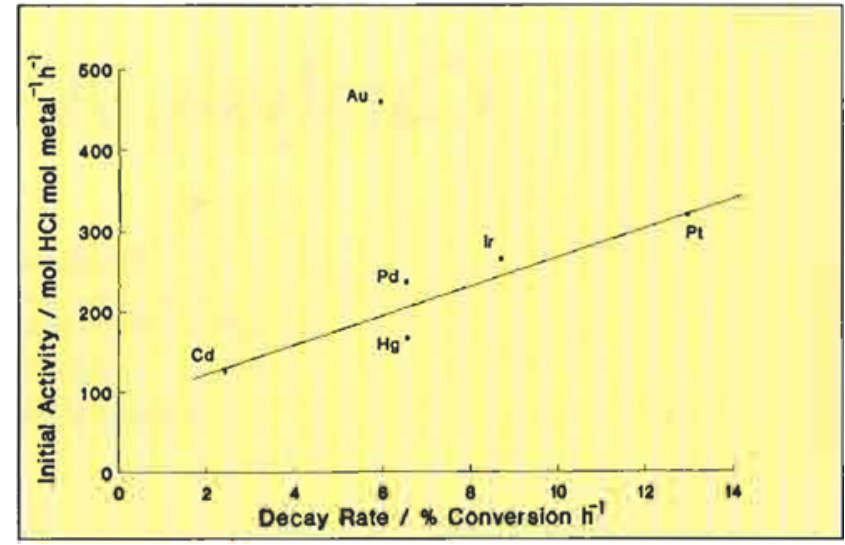

Figure 2 Correlation of bydrochlorination activity of metal chlorides supported on carbon $\left(200^{\circ} \mathrm{C}, \mathrm{GHSV}\right.$ $150 \mathrm{~h}^{-1}$ ) with the standard electrode potential (after reference 16 ).

However, inspection of the data shows that $\mathrm{Hg}^{2+}, \mathrm{Cd}^{2+}$ and $\mathrm{Zn}^{2+}$ all have similar electron affinities, form complexes with $\mathrm{HCl}$ and can form metastable acetylides. On this basis, it can be argued that the electron affinity was not the correct correlation parameter since this involves a one electron transfer, whereas the bonding of ethyne to a metal surface can involve the transfer of a greater number of electrons. I proposed (16) that the standard electrode potential should be a more suitable parameter for the correlation of catalytic activity and the correlation is shown in Figure 2. The data fall on a smooth curve and can be satisfactorily represented by a single function. The importance of this, is that this correlation can be used predictively, since any metal cation with a higher electrode potential than $\mathrm{Hg}^{2+}$ would be expected to give enhanced catalytic activity. On this basis gold cations would be predicted to be the most active catalysts for this reaction. Subsequent research $(17,18)$ confirmed this prediction (Figure 3) and on an initial rate basis gold catalysts are about three times more active than mercuric chloride catalysts. This was the first example of a reaction for which a gold catalyst was found to exhibit the highest activity.

\section{Hydrochlorination of ethyne using gold catalyst systems}

Active gold-containing catalysts are prepared by impregnation of $\mathrm{HAuCl}_{4}$ solutions onto activated carbon and the best results were obtained if the $\mathrm{HAuCl}_{4}$ was dissolved in aqua regia (19). One unfortunate observation for all metal chloride catalysts for this reaction is that they deactivate with time on stream when used in a standard fixed bed reactor. However, gold catalyst systems have a lower rate of 


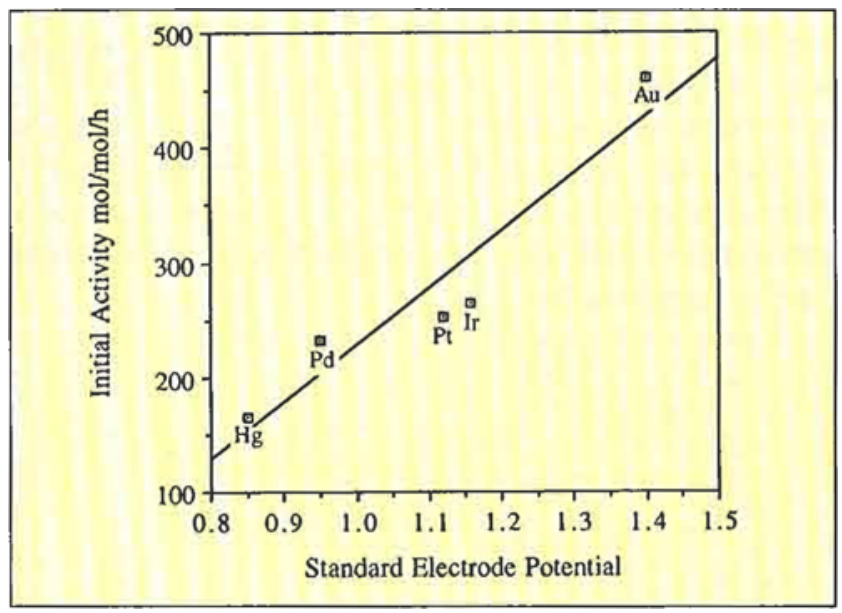

Figure 3 Correlation of hydrochlorination activity of metal chlorides supported on carbon $\left(180^{\circ} \mathrm{C}, G H S V 1140\right.$ $\left.\mathrm{h}^{-1}\right)$ with the standard electrode potential. Catalysts contain 0.0005 mol metall $100 \mathrm{~g}$ catalyst (after reference 19).

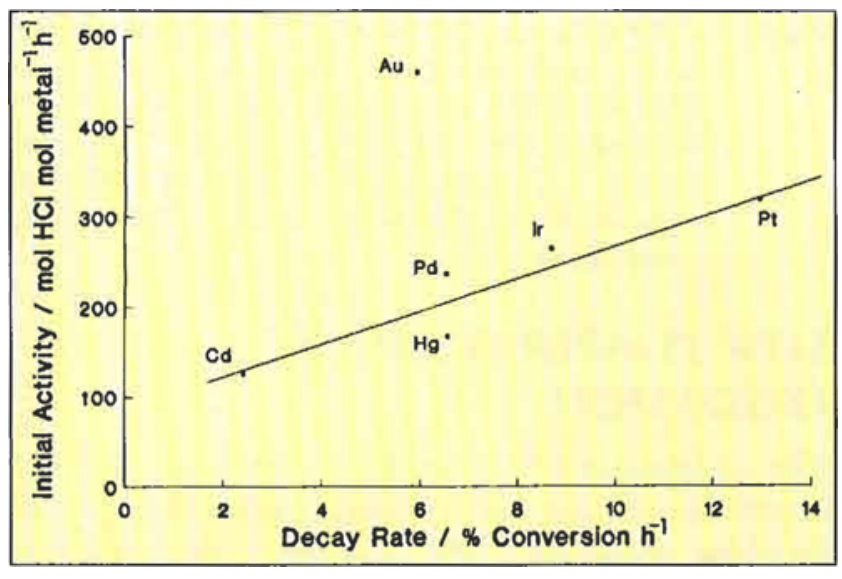

Figure 4 Correlation of initial catalyst activity and conversion decay rate (average loss of conversion (\%) for the initial $3 \mathrm{~h}$ reaction). Catalysts contain $0.0005 \mathrm{~mol}$ metal/100g catalyst (after reference 19).

deactivation than would be expected (Figure 4). Furthermore, the rate of deactivation is significantly decreased for higher gold loadings, although the lowest gold loadings give the highest initial reaction rate (Figure 5). Surprisingly, the deactivation rate is very temperature dependent and high rates of deactivation are observed at both high and low temperatures. The low temperature deactivation is due to coke deposition, probably as a result of surface polymerization reactions of chloroethene and ethyne. The highest reaction rates are observed at $180^{\circ} \mathrm{C}$, and the cause of the deactivation at this temperature was elucidated using ${ }^{197} \mathrm{Au}$ Mössbauer spectroscopy, a technique that is particularly effective for the determination of relative

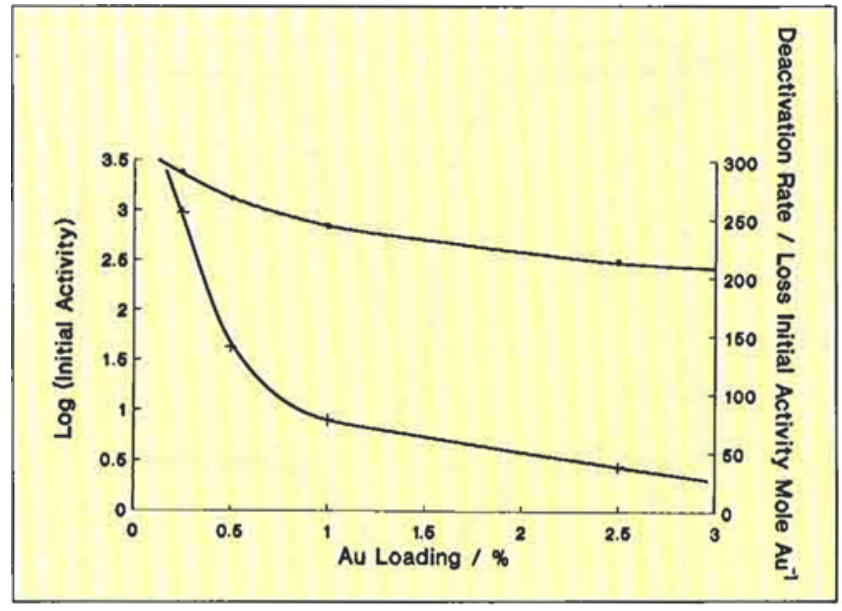

Figure 5 Effect of $A$ u loading on: + rate of deactivation (loss of activity (mol $\mathrm{HCl}$ converted/mol $\mathrm{Au} / \mathrm{h}$ ) averaged over initial 3h); initial activity ( $\mathrm{mol} \mathrm{HCl}$ converted/mol Aulh at 0.5 h). (180 $\mathrm{C}$, GHSV $1140 \mathrm{~h}^{-1}$ ) (after reference 19).

concentrations of $\mathrm{Au}(0), \mathrm{Au}(\mathrm{I})$ and $\mathrm{Au}(\mathrm{III})$ present in the catalysts. These studies confirmed that deactivation at the higher temperature was due to reduction of $\mathrm{Au}$ (III) to metallic gold (Figure 6). In addition, $\mathrm{Au}(\mathrm{I})$ was also observed to be present in these catalysts. Studies using catalysts containing only $A u(0), A u(I)$ and both $A u(I I I)$ and $A u(0)$ (it was not possible to prepare catalysts containing only $\mathrm{Au}(\mathrm{III})$ ) showed that the rate of reaction decreased in the order $\mathrm{Au}(\mathrm{III})>\operatorname{Au}(\mathrm{I})>\operatorname{Au}(0)$.

Deactivation is a common operational problem for heterogeneous catalysts and in such circumstances it is important to devise a strategy for reactivation so that the catalyst can be continued to be used. In our previous studies with mercuric chloride catalysts we found that some activity could be restored with an offline $\mathrm{HCl}$ treatment of the catalyst at $\geq 180^{\circ} \mathrm{C}$. However, a principle cause for activity loss was found to be loss of mercuric chloride from the catalyst during use (11) leading to gradual deterioration of the catalyst. This is not the case for the gold catalyst since under the reaction conditions employed no gold is lost from the catalyst, and deactivation is mainly due to reduction of both $A u(I I I)$ and $A u(I)$ to $A u(0)$ (19). For gold catalysts, off-line $\mathrm{HCl}$ treatment of the catalyst at $\geq 180^{\circ} \mathrm{C}$ did restore some activity but, as such a treatment could not oxidize Au, full activity was not restored. Treatments of the deactivated catalyst off-line with $\mathrm{Cl}_{2}, \mathrm{NO}$ and $\mathrm{N}_{2} \mathrm{O}$ at elevated temperatures $\left(\geq 180^{\circ} \mathrm{C}\right)$ were effective and the best results were obtained using NO. However, the most important observation was that $\mathrm{NO}$ could be fed 


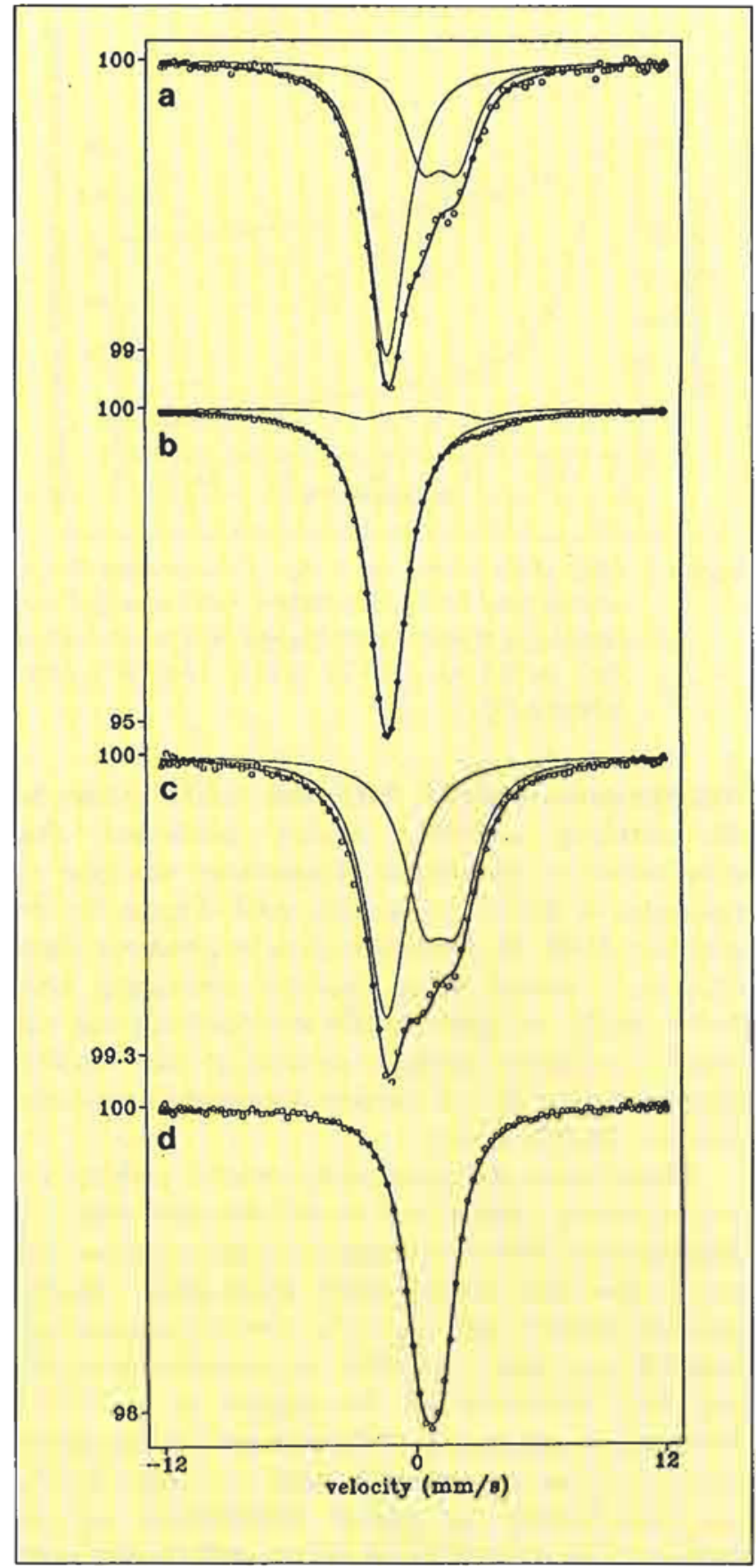

Figure $6{ }^{197} \mathrm{Au}$ Mössbauer spectra of (a) $2 \% \mathrm{HAuCl}_{4}$ adsorbed on activated carbon from aqua regia solution, (b) the same catalyst after deactivation at $180^{\circ} \mathrm{C}, \mathrm{GHSV}$ $1140 \mathrm{~h}^{-1}$, for $6 \mathrm{~h},(\mathrm{c})$ a sample of the same type after reactivation by boiling in aqua regia, and (d) crystalline $\mathrm{HAuCl}_{4} \times \mathrm{H}_{2} \mathrm{O}$ (after reference 19). together with the reactants (Figure 7), and deactivation was virtually eliminated, and there was no effect on chloroethene selectivity (20). In this way the gold catalysts can be used for extended reaction periods. This represents a very interesting example of on-line reactivation and may be applicable to other gold catalysis applications.

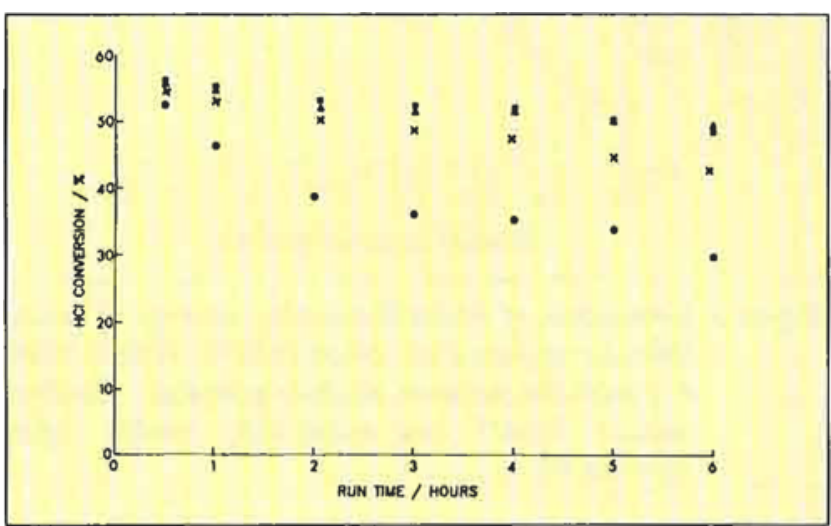

Figure 7 Effect of in situ reactivation of supported Au catalysts using oxidizing gases. Key: $\mathbf{0}$, reaction of $\mathrm{C}_{2} \mathrm{H}_{2} / H C l / N O$; $\Delta$, following reactivation off line reactivation with $N O, 180^{\circ} \mathrm{C}, 6 \mathrm{~h}, \mathrm{GHSV640 \textrm {h } ^ { - 1 }}$; $\bullet$, reaction of $\mathrm{C}_{2} \mathrm{H}_{2} / \mathrm{HCl} / \mathrm{N}_{2}$ following off line reactivation with $\mathrm{NO} ; \mathbf{*}$, reaction of $\mathrm{C}_{2} \mathrm{H}_{2} / \mathrm{HCl} / \mathrm{N}_{2} \mathrm{O}$ (after reference 20).

\section{LOW TEMPERATURE CO OXIDATION}

The oxidation of $\mathrm{CO}$ at ambient temperature is a very important reaction for air purification systems and breathing apparatus. The industrial catalyst used at present is hopcalite $(21,22)$ which is a mixed oxide of copper and manganese, $\mathrm{CuMn}_{2} \mathrm{O}_{3}$, but this catalyst deactivates quite rapidly and is unsuitable for long term use. Certain applications require the catalyst to survive and remain effective for many weeks, e.g. in the purification of air in long duration space travel. The prospect of such travel becoming a reality has been rekindled by the recent observation that life may have existed on Mars, and it is exciting to think that catalysis may play a role in future space exploration. There is another reason for the intense interest in low temperature $\mathrm{CO}$ oxidation and this concerns the low temperature performance of car exhaust catalysts. On start-up car exhaust catalysts take a little time to become effective, and this is mainly due to the time required to heat the catalyst using the exothermicity of the combustion reactions. If a catalyst component could be added that was effective for combustion at lower temperatures, then this initial warm-up period could be shortened. 


\section{CO oxidation using gold catalysts}

Haruta $(23,24)$ was the first to show that gold catalysts could be effective at ambient remperature. $\mathrm{He}$ noted (24) that gold catalysts prepared using a conventional impregnation procedure were considerably less active than platinum group metals prepared in a similar way. It is probably for this reason that gold was then overlooked by many researchers as an oxidation catalyst. Haruta showed that the method of catalyst preparation was very important and that if a co-precipitation procedure was utilized, high activity catalysts were obtained. The catalysts were prepared from addition of an aqueous solution of chloroauric acid and a metal nitrate to an aqueous sodium carbonate solution. The precipitate was then washed, vacuum dried and calcined at $400^{\circ} \mathrm{C}$. In addition, Haruta (25) has also shown that catalysts can be prepared using deposition precipitation. Haruta tested a range of metal oxide supports (Figure 8) and observed that the best results were obtained with $\alpha-\mathrm{Fe}_{2} \mathrm{O}_{3}$ as support and with a gold loading of $5 \%$. Indeed, Haruta observed that this catalyst was effective at sub-ambient temperatures and activity was observed at temperatures even as low as $-76^{\circ} \mathrm{C}$. However, except for a few reports of activity being observed at these low temperatures, recent research papers have concentrated on the use of ambient temperatures or temperatures up to $80^{\circ} \mathrm{C}$. The detailed work of Haruta has led to an understanding of the improved catalytic activity of the co-precipitated catalysts. He has found that this method results in a very uniform dispersion of small metallic gold particles on the support. The best results are obtained when these particles are $c a .5 \mathrm{~nm}$ in diameter (26) and when reaction temperatures of $>55^{\circ} \mathrm{C}$ are used.

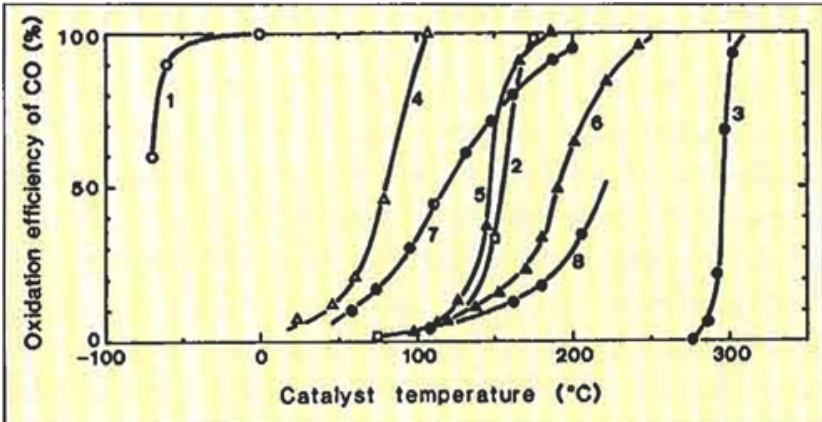

Figure 8 Oxidation efficiencies of $\mathrm{CO}$ over various catalysts as a function of temperature. Key: $1, \mathrm{Au}_{\alpha}-\mathrm{Fe}_{2} \mathrm{O}_{3}$ (Au/Fe $=1 / 19$, co-precipitation); 2, $0.5 w t \%$ $\mathrm{Pdh} \mathrm{Al}_{2} \mathrm{O}_{3}$ (impregnation): 3, Au fine powder; 4, $\mathrm{Co}_{3} \mathrm{O}_{4}$ (ex carbonate); 5, $\mathrm{NiO} ; 6 \alpha-\mathrm{Fe}_{2} \mathrm{O}_{3} ; 7,5$ $w t \% A u / \alpha-\mathrm{Fe}_{2} \mathrm{O}_{3}$ (impregnation); 8, $5 w t \% A u / \gamma$ $\mathrm{Al}_{2} \mathrm{O}_{3}$ (impregnation) (after reference 24).

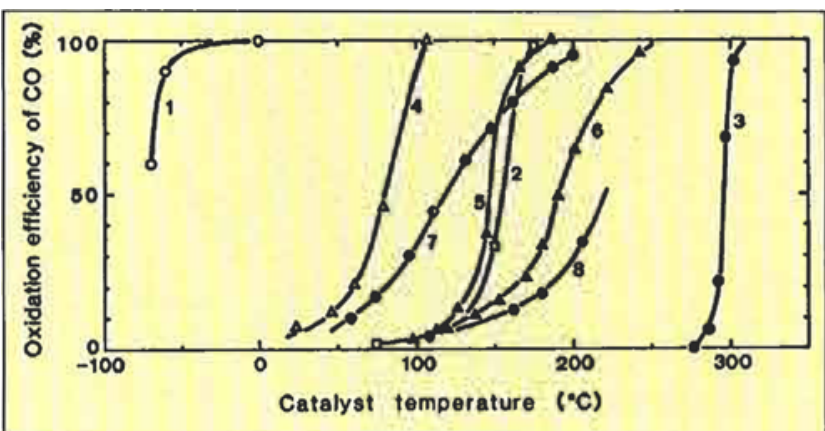

Figure 9 Catalytic performance for $\mathrm{CO}$ oxidation at $20^{\circ} \mathrm{C}$ (0.45\% CO, GHSV = 33000h $\left.{ }^{-1}\right) \mathrm{Key}:$ 口 $\mathrm{Au} / \mathrm{ZnO}$; -, $\mathrm{Au} / \mathrm{CuO}$; , $\mathrm{Au} / \mathrm{CuO} / \mathrm{ZnO}$; +, CuO/ZnO (aged $300 \mathrm{~min}$ ); $\Delta, \mathrm{CuO} / \mathrm{ZnO}$ (aged $30 \mathrm{~min}$ ) (after reference 31 ).

Subsequent studies by Gardner et al. (27) confirmed the high activity of gold catalysts and, in particular, contrasted the high activity gold catalysts with a supported platinum catalyst. They showed that the gold catalysts were more active than the platinum catalyst by a factor of five. One of the main problems for supported gold catalysts for this reaction is deactivation. All Au/metal oxide catalysts deactivate during $\mathrm{CO}$ oxidation, and particularly when $\mathrm{CO}_{2}$ is present in the feed. This is of course a major problem for breathing air applications, since significant $\mathrm{CO}_{2}$ concentrations are present. This problem was highlighted at the recent International Congress on Catalysis in Baltimore by Srinivas et al (28).

We have recently studied the problem of deactivation using our knowledge of the effect of ageing of catalyst precipitation precursors in solution on the eventual catalyst performance for copper-based catalysts $(29,30) . \mathrm{Au} / \mathrm{CuO} / \mathrm{ZnO}, \mathrm{Au} / \mathrm{ZnO}$ and the $\mathrm{Au} / \mathrm{CuO}$ catalysts were prepared using a coprecipitation method in which the initial precipitate is stirred, i.e. aged, in the solution for $180 \mathrm{~min}$ prior to recovery and washing. These catalysts are found to give sustained activity (31) without deactivation during the $800 \mathrm{~min}$ experimental test (Figure 9). The nonAu-containing $\mathrm{CuO} / \mathrm{ZnO}$ catalyst prepared using the same co-precipitation process displays a much lower activity and a general decline in $\mathrm{CO}$ conversion together with oscillations in catalytic activity. Such phenomena have been noted previously for nonAu-containing catalysts for this reaction (32). Examination of the catalysts by electron microscopy showed that no morphological differences were observed between any particular used catalyst and its unused counterpart. A common characteristic of all 


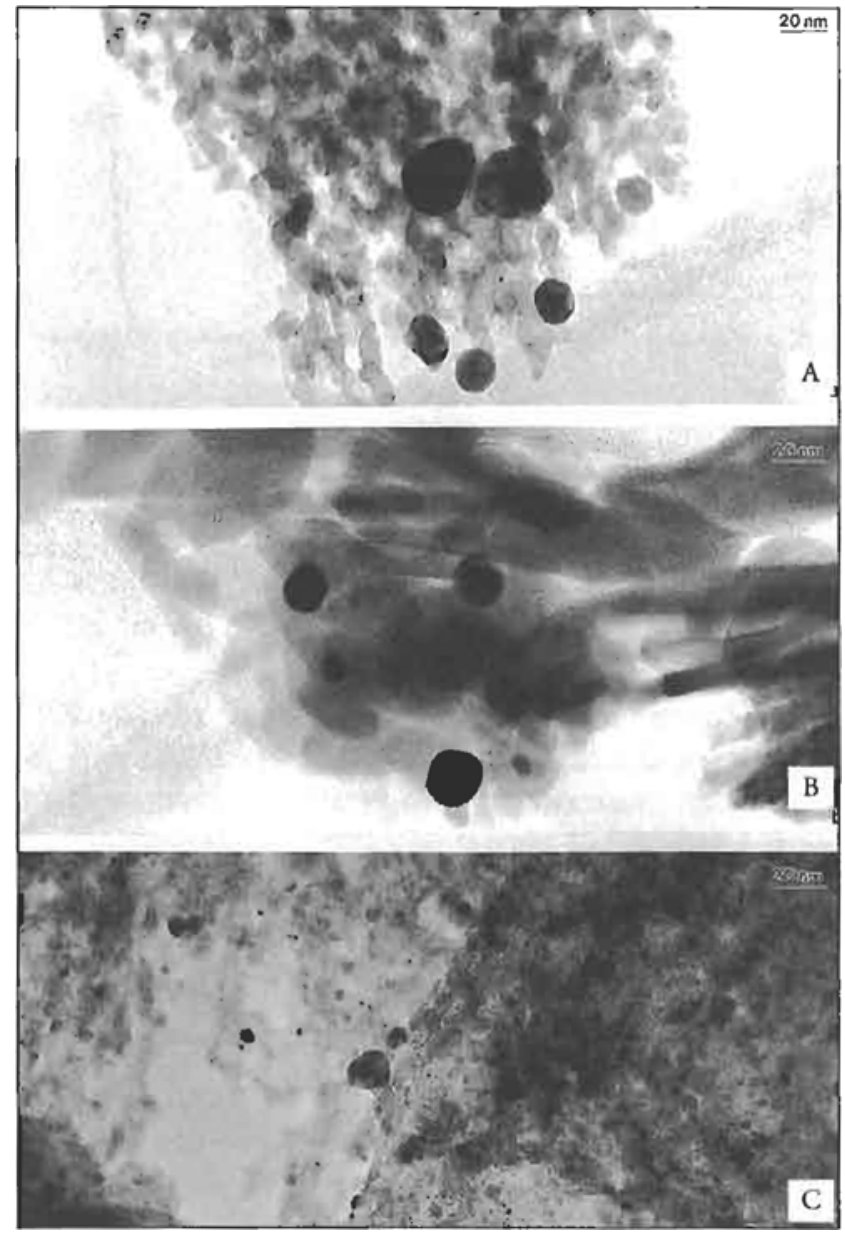

Figure 10 Representative bright field TEM micrographs of catalysts of Figure 9 after reaction, key: (a) $A u / C u O$, (b) $A u / C u O / Z n O$, (c) $A u / Z n O$ (after reference 31).

the catalysts is the presence of discrete Au particles which frequently exhibit multiple twinning (Figure 10). There is, however, a distinct difference in the sizes and dispersion of the Au particles in these different catalysts. The largest Au particles are observed with the $\mathrm{Au} / \mathrm{CuO}$ catalyst (Figure 10a) where the mean $\mathrm{Au}$ particle size is ca. 20-30 $\mathrm{nm}$ and there are many particles as large as $50 \mathrm{~nm}$. Similarly, relatively large Au particles are found in the $\mathrm{Au} / \mathrm{CuO} / \mathrm{ZnO}$ catalyst (Figure 10b), although in this case they are supported on aurichalcite $\left(\mathrm{Cu}_{\mathrm{x}} \mathrm{Zn}_{1-\mathrm{x}}\right)_{5}\left(\mathrm{CO}_{3}\right)_{2}(\mathrm{OH})_{6}$ needles and rosasite $\left(\mathrm{Cu}_{\mathrm{x}} \mathrm{Zn}_{1-\mathrm{x}}\right)_{2}\left(\mathrm{CO}_{3}\right)(\mathrm{OH})_{2}$ platelets. However, the best catalytic performance is obtained with the $\mathrm{Au} / \mathrm{ZnO}$ catalyst in which much smaller Au particles (mean particle size is $2.5 \mathrm{~nm}$ ) are supported on feathery zinc-containing crystallites (Figure 10c).

We consider that the method of co-precipitation used is important for the attainment of the sustained high activity catalysts. In the earlier work by Haruta et al $(24,31)$, the catalysts were prepared using a precipitation method in which the precipitate was not aged in the solution, i.e. the precipitate was recovered immediately after the precipitation step rather than allowing it to remain in contact with the precipitating solution for an extended time period. Earlier studies had shown that the ageing of the $\mathrm{CuO} / \mathrm{ZnO}$ precipitate can be crucial with respect to the formation of an active catalyst for the hydrogenation of $\mathrm{CO}$ to methanol and in general the preferred catalysts are produced from a precursor that has been aged for at least $180 \mathrm{~min}$ (29). When $\mathrm{Au}$ is present in the coprecipitation mixture the initial precipitate that forms is amorphous. During the ageing process the precipitate gradually crystallizes and it is these more crystalline materials that give enhanced activity. The sustained high activity of these catalysts is evident in that the $\mathrm{CO}$ conversion for the $2 \% \mathrm{Au} / \mathrm{ZnO}$ catalyst is typically $>90 \%$ over the test period and the rate of CO oxidation is typically $6 \mathrm{~mol} / \mathrm{kg}$ catalyst $/ \mathrm{h}$. Although the previously cited Au catalysts, prepared by co-precipitation without an ageing step, can generally give initial $\mathrm{CO}$ conversions that are equivalent, they are known to deactivate rapidly at $20^{\circ} \mathrm{C}$ and half lives of only 100-200 min are observed. Our recent results have not been optimized but they are indicative of the improved catalytic performance that can be achieved using a method of preparation that is a combination of the co-precipitation procedure together with controlled ageing of the precipitate.

\section{USE OF SUPPORTED GOLD CATALYSTS FOR OTHER REACTIONS AND APPLICATIONS}

In early studies, Haruta (24) showed that the coprecipitated gold catalysts were also effective in the oxidation of hydrogen, a reaction of considerable importance with respect to fuel cells. More recently, Haruta has investigated the oxidation of hydrocarbons such as propene (26), and the hydrogenation of $\mathrm{CO}_{2}$ to methanol using gold catalysts $(33,34)$. He has also extended these studies to methanol combustion (35). Another important emerging application for these supported gold systems concerns their use as potential CO detection sensors, a subject of current interest (36-38). The reduction of $\mathrm{NO}$ with propene over $\mathrm{Au} / \mathrm{Al}_{2} \mathrm{O}_{3}$ catalysts, in the presence of excess oxygen and moisture has also been reported (39). 


\section{CONCLUSIONS}

Recent research shows that for a number of reactions gold can provide the highest catalytic activity when compared with other metals. In one specific case, the hydrochlorination of ethyne, the high catalytic activity of gold was predicted from a correlation between activity and the standard reduction potential. However, a more general reason for the observation of high catalytic activity for gold has been the identification that specific controlled catalyst preparation methods are required if the optimum performance is to be obtained from gold catalysts. For the hydrochlorination of ethyne, it is important that the oxidation state of gold is maximized and techniques involving the impregnation of $\mathrm{Au}$ (III) from aqua regia solutions give the best results. For low temperature $\mathrm{CO}$ oxidation, small uniform Au metal particles are a prerequisite for high activity and in this case co-precipitation gives the best results. Prior to these studies gold was considered to give poor catalytic performance but it now seems probable that this was a catalyst preparation problem. It is clear that gold will find further applications in catalysis now that it has graduated to being a catalyst of choice for these two reactions.

\section{ACKNOWLEDGEMENTS}

A number of students and colleagues have contributed to the gold catalysis studies cited from the work of my research group. The hydrochlorination work was carried out in collaboration with Bongani Nkosi, Neil Coville, Mike Adams and Fritz Wagner. The low temperature $\mathrm{CO}$ oxidation study was carried out in collaboration with Robin Whyman, Christopher Kiely, Andy Burrows and Raffiq Siddiqui.

\section{ABOUT THE AUTHOR}

Professor Graham Hutchings is Deputy Director of the Leverhulme Centre for Innovative Catalysis at the University of Liverpool. He has experience in both academic and industrial catalysis research and has a current research interest in oxidation chemistry.

\section{REFERENCES}

1 G.C. Bond, Gold Bull., 1972, 5, 11

2 J. Schwank, Gold Bull., 1985, 18, 1

3 F. Gasparrini, M. Giovannoli, D. Misiti, G. Natile and G. Palmierri, Tetrahedron, 1983, 39, 3181
4 F. Gasparrini, M. Giovannoli, D. Misiti, G. Natile and G. Palmierri, Tetrahedron, 1984, 40, 165

5 J.W.A. Sachtler, M.A. Van Hove, J.P. Biberian and G.A. Somorjai, Phys. Rev. Lett., 1980, 45, 1601

6 J.R.H. Schaik, R.P. Dressing and V. Ponec, J. Catal., 1975, 38, 273

7 D. Thompson, Gold Bull., 1996, 39, 94

8 A.I. Gel'bshtein, M.I. Siling, G.G. Shcheglova and I.B. Vasil'eva, Kinet. Catal., 1964, 5, 402

9 D.M. Smith, P.M. Walsh and T.L. Slager, J. Catal., 1968, 11, 113

10 K. Shinoda, Chem. Lett., 1975, 219

11 G.J. Hutchings and D. Grady, Appl. Catal., 1985, 16,441

12 G.J. Hutchings and D. Grady, Appl. Catal., 1985, 17, 155

13 A.I. Gel'bshtein, M.I. Siling, G.A.Sergeeva and G.G. Shcheglova, Kinet. Catal., 1963, 4, 123

14 A.I. Gel'bshtein and M.I. Siling, Kinet. Catal., $1963,4,262$

15 A.I. Gel'bshtein, G.G. Shcheglova and A.A. Khomenko, Kinet. Catal., 1964, 4, 543

16 G.J. Hutchings, , J. Catal., 1985, 96, 292

17 B. Nkosi, N.J. Coville, and G.J. Hutchings, J. Chem. Soc., Chem. Commun., 1988, 71

18 B. Nkosi, N.J. Coville and G.J. Hutchings, Appl. Catal., 1988, 43, 33

19 B. Nkosi, N.J. Coville G.J. Hutchings, M.D. Adams, J. Friedl and F. Wagner, J. Catal., 1991, 128, 366

20 B. Nkosi, M.D. Adams, N.J. Coville and G.J. Hutchings, J. Catal., 1991, 128, 378

21 S. Veprek, D.L. Cocke, S. Kehl and H.R. Oswald, J. Catal., 1986, 100, 250

22 G.J Hutchings, A.A Mirzaei, R.W Joyner, M.R.H. Siddiqui and S.H. Taylor, Catal. Lett., in press

23 M. Haruta, T. Kobayashi, H. Sano and N. Yamada, Chem. Lett., 1987, 405

24 M. Haruta, N. Yamada, T. Kobayashi and S. Ijima, J. Catal., 1989, 115, 301

25 M. Haruta, S. Tsubota, T. Kobayashi, H. Kageyama, M.J. Genet and B. Delmon, J. Catal., $1993,144,175$

26 M. Haruta, A. Ueda, R.M. Torres Sanchez and K. Tanaka, Prp. Pet. Div., ACS Symp., New Orleans, 1996; T. Hayashi, K. Tanaka and M. Haruta, Prp. Pet. Div., ACS Symp., New Orleans, 1996

27 S.D. Gardner, G.B. Hoflund, B.T. Upchurch, D.R. Schryer, E.J. Kielen and J. Schryer, J. Catal., 1991, 129, 114 
28 G. Srinivas, J. Wright, C.-S. Bai and R. Cook, Stud.Surf. Sci. Catal., 1996, 101, 427

29 R.W. Joyner, F. King, M.A. Thomas and G. Roberts, Catal. Today, 1991, 10, 417

30 A.A. Mirzai, M.R.H. Siddiqui, S.H. Taylor, C.J. Kieley, A. Burrows, R.W. Joyner and G.J. Hutchings, in preparation

31 G.J. Hutchings, M.R.H. Siddiqui, A. Burrows, C.J. Kiely and R. Whyman, J. Chem. Soc., Faraday Trans., in press

32 F. Boccuzzi, A. Chiorino, S. Tsubota and M. Haruta, Catal. Lett., 1994, 29, 225

33 H. Sakurai, S. Tsubota and M. Haruta, Appl. Catal., 1993, 102, 125
34 H. Sakurai and M. Haruta, Catal. Today, 1996, 29, 361

35 M. Haruta, A.Ueda, S. Tsubota and R.M. Torres Sanchez, Catal. Today, 1996, 29, 443

36 T. Kobayashi, M. Haruta, S. Tsubota and H. Sano, Sensors. Act., 1987, B1, 222

37 M. Ando, T. Kobayashi and M. Haruta, 5th Int. Meet. Chem. Sensors, 1994, 1156

38 F. Boccuzzi, A. Chiorino, S. Tsubota and M. Haruta, Sensors. Act., 1995, B24-25, 540

39 A. Ueda, T. Oshima and M. Haruta, Environ. Catal., 1995, 343

\section{Spacing Nanoparticles of Gold Using DNA}

Nanotechnology has potential applications in electronics, computing, sensors and catalysis $(1,2)$ and is exciting public interest (3). Good progress has been made on devising methods for controlling the chemical composition, size and dispensability of colloidal particles, and methods are now being developed for assembling them into useful aggregates and materials. Following work at Liverpool University, UK on the preparation of thiol-derivatized gold nanoparticles (1), two papers published in the same issue of Nature $(3,4)$ from the University of California, Berkeley, and North-Western University, Illinois, in the USA indicate how molecules of DNA capped with thiol can be used to control the spacing between gold particles.

Alivisatos et al (4) point out that patterning matter on the nanometre scale is an important step towards further miniaturizing electronic components. At the nanometre scale materials properties are strongly size-dependent and can be sensitively tuned. A strategy is described for the synthesis of 'nanocrystal molecules' in which discrete numbers of gold nanocrystals are organized into spatially-defined structures based on Watson-Crick base-pairing interactions. Single stranded DNA oligonucleotides of defined length and sequence are attached to individual nanocrystals, and these assemble into dimers and trimers on addition of a complementary single-stranded DNA template. The extension of this approach to the construction of more complex two and three dimensional assemblies is forecast.
The method described by Mirkin et al (5) involves attaching to the surface of two batches of $13 \mathrm{~nm}$ gold particles, non-complementary DNA oligonucleotides capped with thiol groups, which bind to gold (1). On addition of a solution of an oligonucleotide duplex with 'sticky ends' that are complementary to the two grafted sequences, the nanoparticles self assemble into aggregates. It is forecast that use of the specificity of DNA interactions to direct the interactions between particles of different size and composition could make it possible to tailor the optical, electronic and structural properties of the colloidal aggregates. The colloidal particles of gold have large extinction coefficients for the bands which give rise to their colours; and these intense colours, e.g. the so-called 'Purple of Cassius', which depend on particle size, concentration and interparticle distance, suggest that they will find use in new colorimetric sensing and sequencing strategies for DNA.

\section{David Thompson}

\section{REFERENCES}

1 R. Whyman, Gold Bull., 1996, 29, 11

2 G.M. Francis and R.E. Palmer, Gold Bull, $1996,29,47$

3 C. Jones, Financial Times, 15 August 1996

4 A.P. Alivisatos, K.P. Johnson, X. Peng, T.E. Wilson, C.J. Loweth, M.P. Bruchez and P.G. Schultz, Nature, 1996, 382, 607

5 C.A. Mirkin, R.L. Letsinger, R.C. Mucic and J.J. Storhoff, Nature, 1996, 382, 607 